\title{
Research on the Mechanical Behavior of the Biomass Densification Process Based on a Thick-walled Cylinder
}

\begin{abstract}
Yu Wang, * Yu Sun, and Kai Wu
The mechanical behavior of the biomass densification process has noticeable influences on energy consumption and pellet quality. In the authors' previous work, a method was proposed to determine the inner pressure by testing the circumferential strain of the outer die wall. Based on this method, a device was developed with strain gauges in the form of a single pellet unit. With this device, experiments were conducted with wood shavings, rice straw, and wheat straw under different levels of particle size, compression rate, and moisture content. The effects of these factors on the inner pressure were analyzed. The relationships among the inner pressure, pellet density, and specific energy consumption were obtained. Results showed that the pressure ratio increased linearly and then decreased and became constant during the relaxation period. The pressure change during the relaxation period was isotropic. The results could provide mechanical explanations for the phenomena in biomass densification processes.
\end{abstract}

Keywords: Biomass; Densification; Pellets; Single pellet unit

Contact information: School of Mechanical Engineering, Nanjing University of Science and Technology, No. 100 Xiaolingwei Street, Nanjing, 210094 China; *Corresponding author: wy@njust.edu.cn

\author{
Nomenclature \\ $P_{\mathrm{i}} / P_{\mathrm{o}}$ \\ $R_{\mathrm{i}} / R_{\mathrm{O}}$ \\ $\sigma_{\mathrm{r}} / \sigma_{\theta} / \sigma_{1}$ \\ $\varepsilon_{\theta} / \varepsilon_{\theta \mathrm{o}}$ \\ $\mu$ \\ E \\ $F_{\text {n }}$ \\ $F_{\mathrm{b}}$ \\ $P_{\mathrm{n}}$ \\ $P_{\text {ne }}$ \\ $x$ \\ $L$ \\ $R_{\mathrm{p}}$ \\ $M R_{\mathrm{p}}$ \\ $r_{\mathrm{p}}$ \\ $l$ \\ $\rho$ \\ $E_{\mathrm{S}}$ \\ $P S$ \\ $M C$ \\ CR \\ Pressure on the inner/outer die wall \\ Radius of the inner/outer die wall \\ Radial/circumferential/axial stress \\ Circumferential strain/circumferential strain of the outer die wall \\ Poisson's ratio of the die material \\ Young's modulus \\ Compression force \\ Force on the backstop \\ Compression pressure \\ Effective compression pressure \\ Displacement of the pressing shaft \\ Maximum displacement of the pressing shaft \\ Ratio of inner pressure versus compression pressure \\ Maximum ratio of inner pressure versus effective compression pressure \\ Radius of the relaxed biomass pellet \\ Length of the relaxed biomass pellet \\ Pellet density \\ Specific energy consumption for a single trail \\ Particle size \\ Moisture content \\ Compression rate
}




\section{INTRODUCTION}

Energy is one of the most important material foundations for the survival and development of human beings. At present, fossil fuels, such as petroleum and its byproducts, are the most widely used form of energy in the world. However, due to the nonrenewability and uneven distribution of fossil fuels, the energy crisis has become a worldwide problem that most countries must face. Therefore, more attention has been paid to looking for new renewable energy to replace traditional fossil fuels. Biomass energy is classified as green energy because it is solar energy that is transformed and stored by plants through photosynthesis. The biomass can be used to generate electricity and produce biofuels. Due to the low bulk density and irregular shape of the raw material, biomass needs to be compressed into pellets or briquettes with biomass densification technology before further processing.

The main problems in the densification process include high energy consumption and unstable product quality (Holm et al. 2006). Immense research has been conducted to find solutions to these problems. The relevant research can be divided into three parts. The first part is the optimization of the processing parameters. Based on such research, it has been found that proper ranges of parameters, such as moisture content, particle size, and compression rate, could lead to low energy consumption and high pellet quality (Niccolò et al. 2018; Chen et al. 2019). However, the optimal ranges vary for different biomass materials (Whittaker and Shield 2017). The second part is the pretreatment of the raw materials. The methods include torrefaction, hydrothermal pretreatment, and biological pretreatment, among others. It was observed that pretreatment reduced grinding energy and increased product heating value (Rudolfsson et al. 2017; Xia et al. 2019). The third section is the inclusion of process additives. Lignin acts as a natural binder in the densification process (Nanou et al. 2018). The inclusion of extra additives to the process, such as cassava stem powder, plastics, oil, etc., could potentially increase the mechanical strength of the products and reduce energy consumption (Larsson et al. 2015; Emadi et al. 2017; Wang et al. 2019a).

Overall, most studies have been conducted from the angle of the improvement of the densification process. Little attention has been paid to mechanical behavior during the densification process. Holm et al. (2006) developed a model for the compression force along a pellet channel based on elastic mechanics. The model determined that the pressure between the biomass and pellet channel, properties of the materials, and dimensions of the channel had noticeable effects on the compression force. This model was verified with experiments based on a single pellet unit (Holm et al. 2007; Puig-Arnavat et al. 2017). Based on this model, Xia et al. (2014) analyzed the dynamic characteristics of the ring-die densification process and built a model for torque and productivity. Results showed that the compression force affected the energy consumption of the ring-die densification process by affecting the torque. Williams et al. (2018) tested the mechanical properties of biomass pellets made from several different materials. Results showed that Young's Modulus of the pellet is anisotropic and influenced by the strain rate. The structure and dimension of the machine also had influences on the pellet properties and energy consumption (Theerarattananoon et al. 2011; Xia et al. 2016).

By comparing the studies discussed above, it could be found that there are specific relationships between the mechanical behavior of pellets and their densification process. In fact, most of the proposed methods improve the densification process by changing the mechanical characteristic of the materials. Therefore, more attention should be paid to the 
mechanical behavior of the densification process. The investigation may provide essential solutions to the problems in the biomass densification process. The pressure between the biomass and the inner die wall is an important parameter related to the mechanical behavior. However, related research has not yet been reported.

In the authors' previous work, a method was proposed to determine the inner pressure by testing the circumferential strain of the outer die wall (Wang et al. 2019b). The present paper analyzes the stress status of a single die and draws a similar conclusion in a more effective way, which confirms the previous work. Based on this method, a device is developed with strain gauges in the form of a single pellet unit. With this device, experiments are conducted with wood shavings, rice straw, and wheat straw under different levels of particle size, compression rate, and moisture content. Based on the experimental data, the change of the inner pressure during a single densification process are analyzed. The relationships among the inner pressure, pellet density, and specific energy consumption are obtained.

\section{STRESS ANALYSIS}

Utilizing the part of a single pellet die as the object, the stress in the die wall is shown in Fig. 1 (Wang et al. 2019b). It is a plane strain problem, which means that the axial displacement equals 0 . Besides, the pressures on the inner and outer die wall are $P_{\mathrm{i}}$ and $P_{\mathrm{o}}$, respectively. Under this condition, the radial and circumferential stresses are given by Lamé equations as Eq. 1 (Perry and Aboudi 2003).

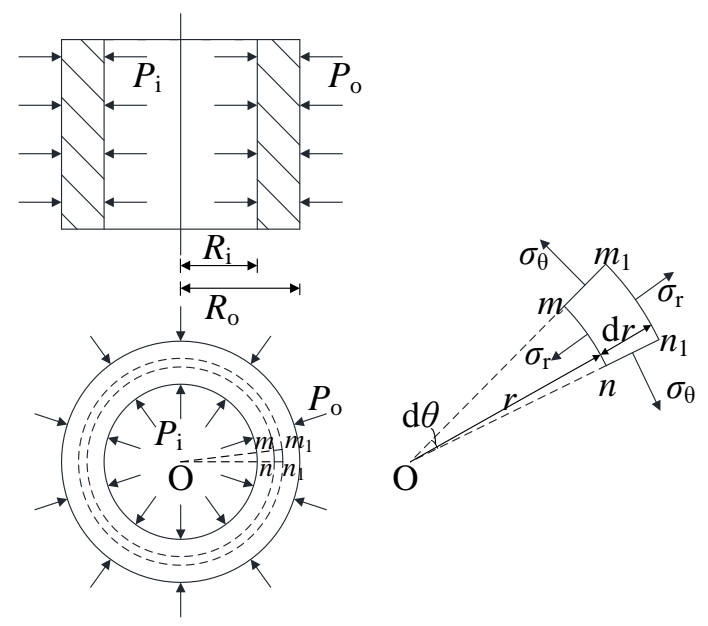

Fig. 1. Stress status of a single die wall

$$
\left\{\begin{array}{l}
\sigma_{\mathrm{r}}=\frac{P_{\mathrm{i}} R_{\mathrm{i}}^{2}-P_{\mathrm{o}} R_{\mathrm{o}}^{2}}{-R_{\mathrm{i}}^{2}+R_{\mathrm{o}}^{2}}-\frac{\left(P_{\mathrm{i}}-P_{\mathrm{o}}\right) R_{\mathrm{i}}^{2} R_{\mathrm{o}}^{2}}{\left(-R_{\mathrm{i}}^{2}+R_{\mathrm{o}}^{2}\right) r^{2}} \\
\sigma_{\theta}=\frac{P_{\mathrm{i}} R_{\mathrm{i}}^{2}-P_{\mathrm{o}} R_{\mathrm{o}}^{2}}{-R_{\mathrm{i}}^{2}+R_{\mathrm{o}}^{2}}+\frac{\left(P_{\mathrm{i}}-P_{\mathrm{o}}\right) R_{\mathrm{i}}^{2} R_{\mathrm{o}}^{2}}{\left(-R_{\mathrm{i}}^{2}+R_{\mathrm{o}}^{2}\right) r^{2}} \\
\sigma_{\mathrm{l}}=0
\end{array}\right.
$$

In Eq. $1, P_{\mathrm{i}}$ and $P_{\mathrm{o}}$ are pressures on the inner and outer die wall $(\mathrm{Pa}), R_{\mathrm{i}}$ and $R_{\mathrm{o}}$ are the radii of the inner and outer die wall $(\mathrm{m}), r$ is the distance between the differential 
volume element and the center $(\mathrm{m})$, and $\sigma_{\mathrm{r}}, \sigma_{\theta}$, and $\sigma_{1}$ are the radial, circumferential, and axial stress $(\mathrm{Pa})$, respectively.

According to Hooke's law, the circumferential strain in the die wall is shown as Eq. 2 ,

$$
\varepsilon_{\theta}=\frac{1}{E}\left[\sigma_{\theta}-\mu\left(\sigma_{\mathrm{r}}+\sigma_{\mathrm{l}}\right)\right]
$$

where $E$ is Young's modulus and $\mu$ is Poisson's ratio of the die material.

Based on Eqs. 1 and 2, the circumferential strain in the die wall can be expressed as:

$$
\varepsilon_{\theta}=\frac{1}{E\left(R_{\mathrm{o}}^{2} / R_{\mathrm{i}}^{2}-1\right)}\left((1-\mu)\left(P_{\mathrm{i}}-\frac{R_{\mathrm{o}}^{2}}{R_{\mathrm{i}}^{2}} P_{\mathrm{o}}\right)+\frac{(1+\mu)\left(P_{\mathrm{i}}-P_{\mathrm{o}}\right) R_{\mathrm{o}}^{2}}{r^{2}}\right)
$$

To simplify Eq. 3, the pressure on the outer die wall is set as 0 during the design of the test device $\left(P_{\mathrm{o}}=0\right)$. Thus, the circumferential strain of the outer die wall is expressed as Eq. 4 when $r$ equals $R_{\mathrm{o}}$,

$$
\varepsilon_{\theta \mathrm{o}}=\frac{2 P_{\mathrm{i}}}{E\left(R_{\mathrm{o}}^{2} / R_{\mathrm{i}}^{2}-1\right)}
$$

where $\varepsilon_{\theta \mathrm{o}}$ is the circumferential strain of the outer die wall.

Therefore:

$$
P_{\mathrm{i}}=\frac{E \varepsilon_{\theta \mathrm{o}}\left(R_{\mathrm{o}}^{2} / R_{\mathrm{i}}^{2}-1\right)}{2}
$$

Equation 5 displays that the inner pressure can be obtained by testing the circumferential strain of the outer die wall.

\section{EXPERIMENTAL}

\section{Device}

Based on Eq. 5, a device was developed with strain gauges (BX120-5AA, Beijing Sichuanger Construction Testing Technology Development Co., Ltd., Beijing, China) in the form of a single pellet unit. The strain was tested by a Wheatstone bridge with NI 9237 (National Instruments, Austin, TX, USA). As shown in Fig. $2, R_{1}$ and $R_{3}$ are the strain gauges for strain testing, $R_{2}$ and $R_{4}$ are the strain gauges for temperature compensation.

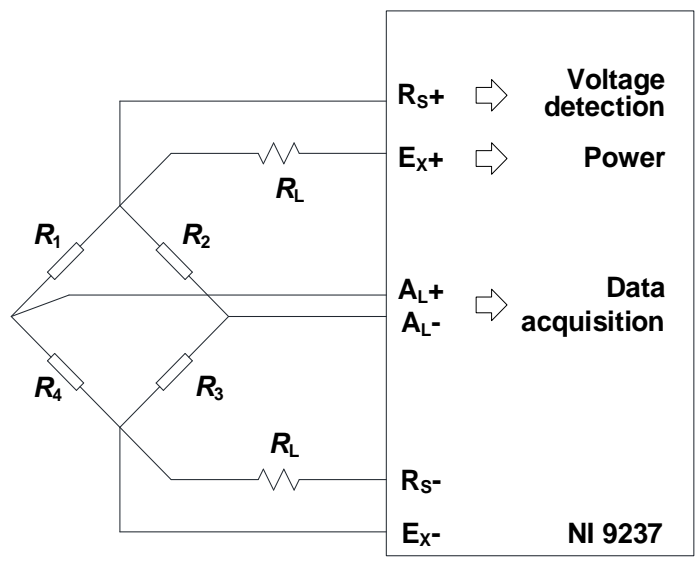

Fig. 2. Connection of the strain gauges 
Two identical dies were produced. One was used to hold the biomass materials during the compression process and fix the strain gauges for strain testing, and another was used to fix the strain gauges for temperature compensation. For the dies in this study, $R_{\mathrm{i}}=$ $0.01 \mathrm{~m}$ and $R_{\mathrm{o}}=0.015 \mathrm{~m}$. The connections of the test system are shown in Fig. 3 .

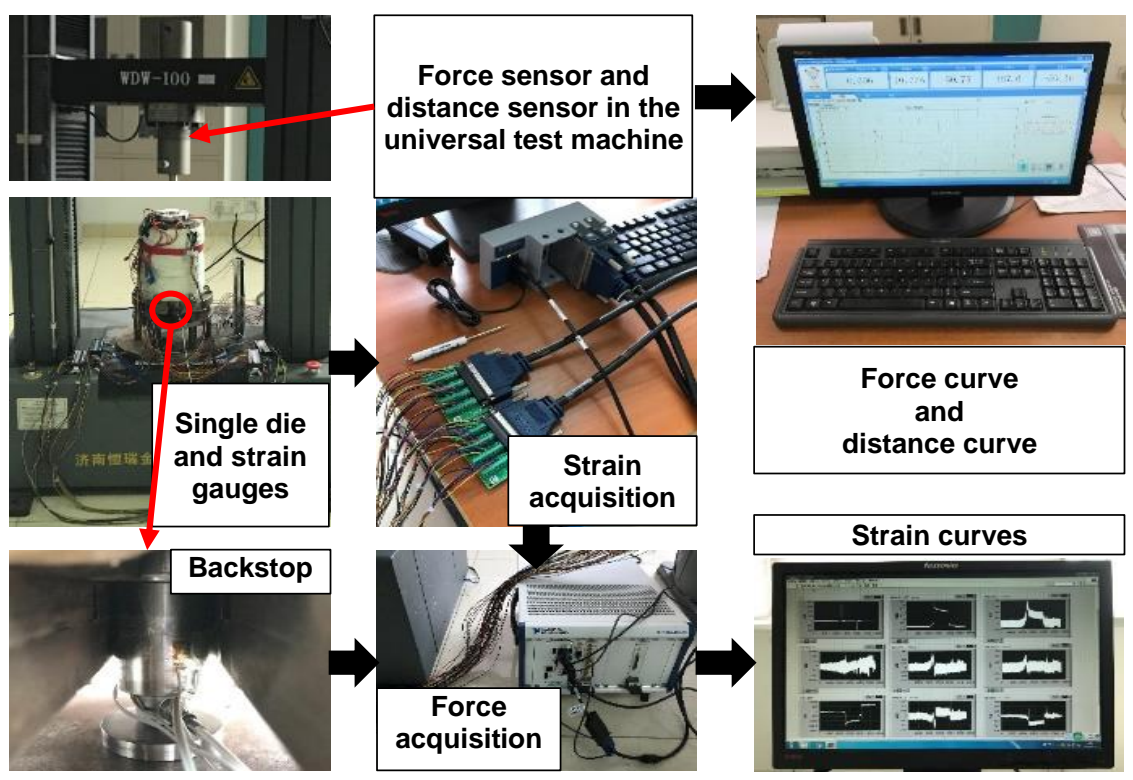

Fig. 3. Connection of the test system

As shown in Fig. 4, the single die was placed in the foundation and then fixed on the static platform of a universal test machine (WDW-100; HRJ Company, Jinan, China). A pressing shaft corresponding to the single die was fixed on the moving part of the universal test machine. A backstop with a force sensor (8712B5000, Kistler Group, Winterthur, Switzerland) was placed under the bottom of the single die.

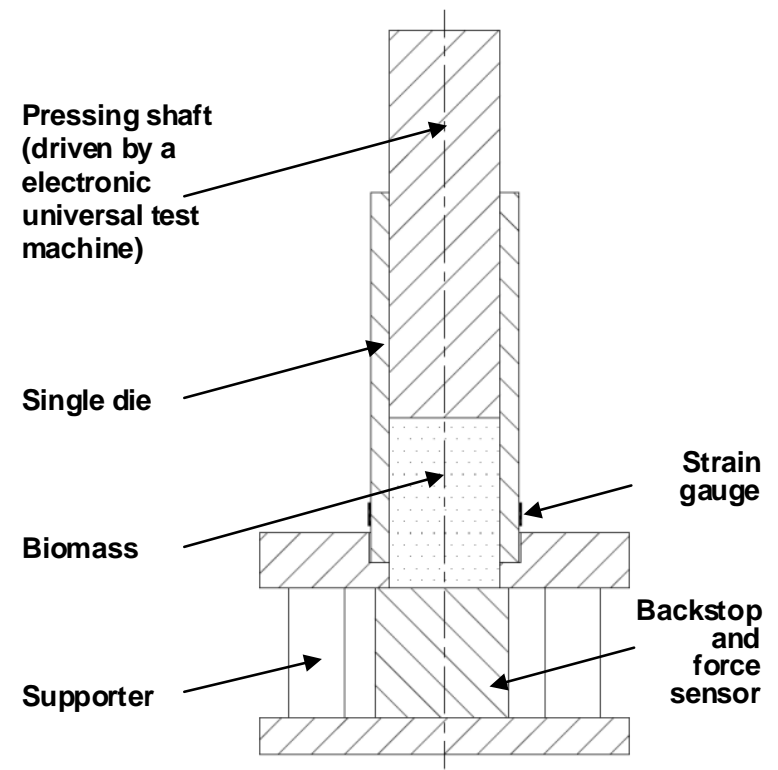

Fig. 4. Schematic sketch of the single pellet unit 
During a single densification process, the biomass materials were first placed in the single die hole. Then, the universal test machine was started. The machine drove the pressing shaft to compress the test materials until the compression force reached $20000 \mathrm{~N}$. The force and distance sensors in the universal test machine were used to record the force and position of the pressing shaft. The force sensor installed in the backstop was used to record the force transmitted from the compressed biomass. The force and strain data were acquired by the NI PXI 4472B (National Instruments, Austin, TX, USA), respectively. The test system is shown in Fig. 5.

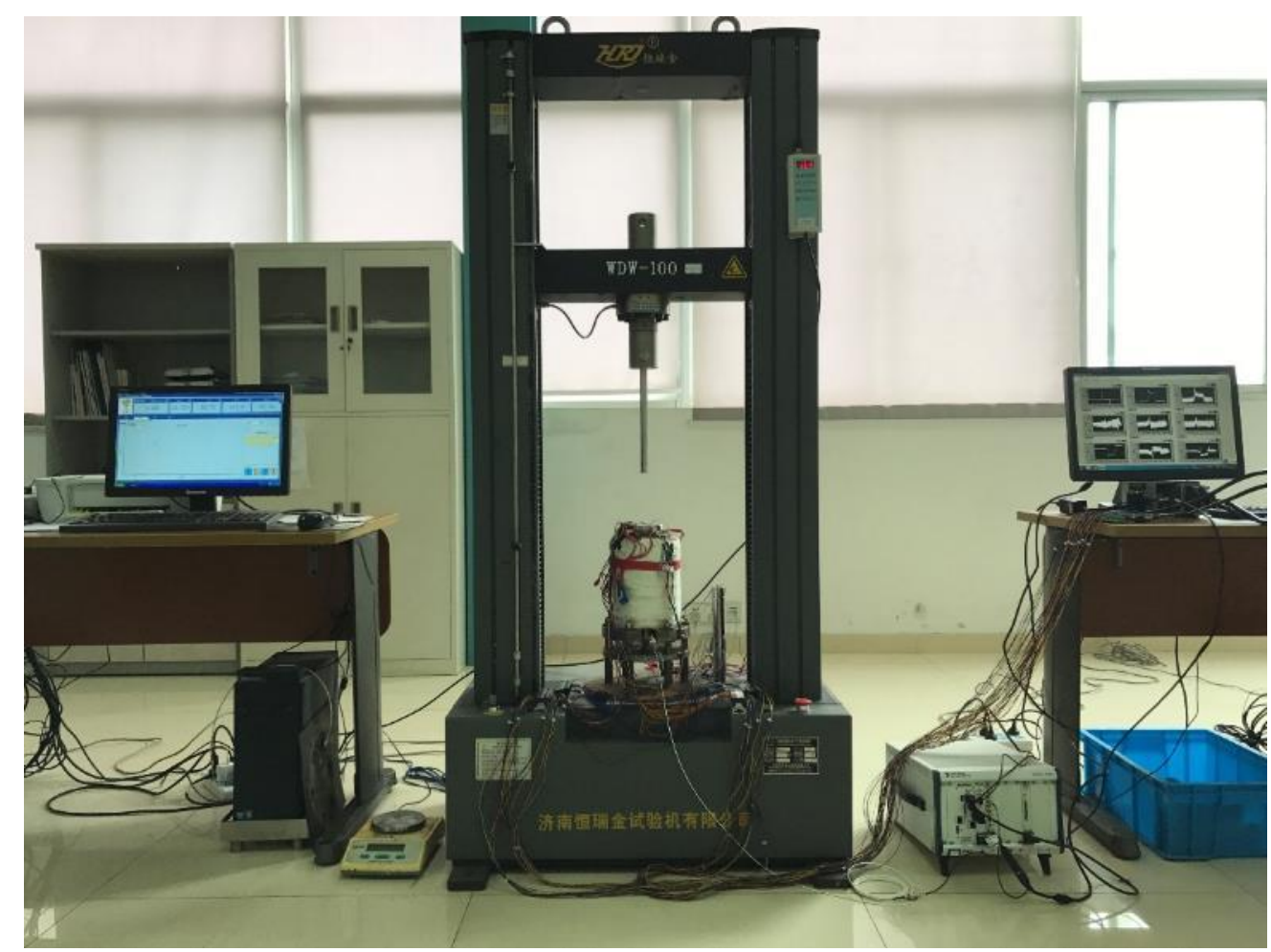

Fig. 5. Test system

\section{Materials}

Three types of biomass materials, including rice straw, wheat straw, and wood shavings, were used in this study. The rice straw and wheat straw were collected in Yangzhou City, China, in January and June of 2019, respectively. The wood shavings were wastes of house decoration obtained in Nanjing City, China, in June of 2019. The raw materials were air-dried under the sun for one day and then stored in sealed black bags. The moisture content of the air-dried materials was tested before the experiment. The average values of the rice straw, wheat straw, and wood shavings were $10.25 \%, 9.84 \%$, and $11.26 \%$, respectively.

Before the experiment, the raw materials were broken into pieces using a lab-scale crusher (DFY-300C, Shanghai Zollo Instruments CO., LTD., Shanghai, China). Then, the crushed materials were sieved for 5 min with a sieve machine (DH-300T, Dahan Vibration Machine, Henan, China). Two different sized sieves ( $2.5 \mathrm{~mm}$ and $5 \mathrm{~mm}$ ) were used in the sieving process. Finally, those materials left above the $5 \mathrm{~mm}$ sieve were collected as the coarse materials, and those passing the $2.5 \mathrm{~mm}$ sieve were collected as the fine materials. Samples of the materials are shown in Fig. 6. The crushed materials were dried with an 
oven under $50{ }^{\circ} \mathrm{C}$ until the mass remained unchanged. Based on the factor levels shown in Table 1, test materials were prepared for each trial by adding water with the help of a moisture meter (SH-10A, Jinghai Instruments, Shanghai, China) (Wang et al. 2017).

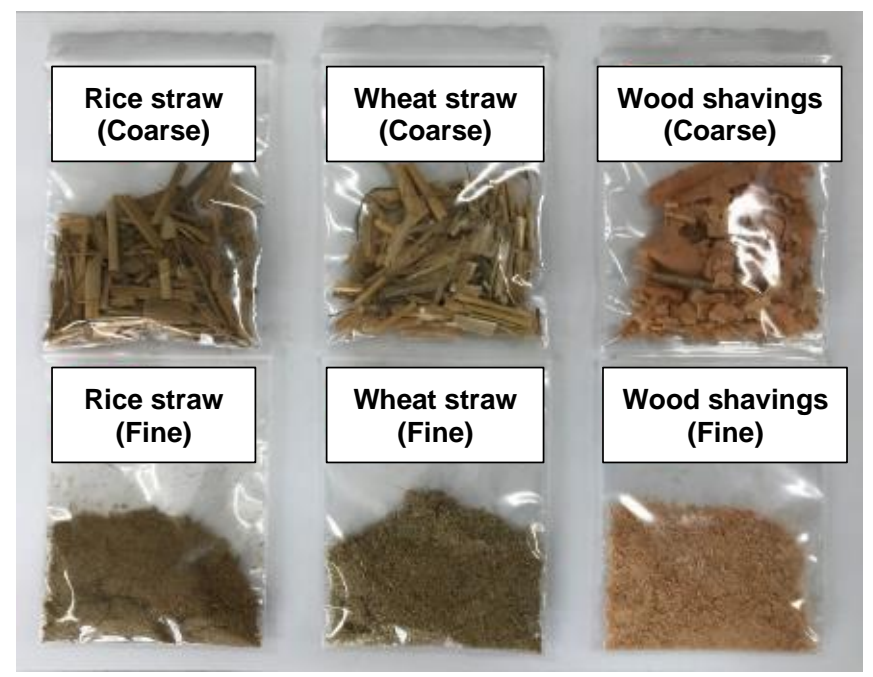

Fig. 6. Samples of the test materials

\section{Factor Levels}

The three factors of particle size, compression rate, and moisture content were considered in this study. The factor levels are shown in Table 1. The test scheme is shown in Table 2. For each trial in the experiment, $3.5 \pm 0.1 \mathrm{~g}$ of the prepared test materials were placed in the single die hole. Then, the universal test machine was started to compress the biomass with a shaft. The shaft was halted when the compression force reached $20000 \mathrm{~N}$. The force was held for $1 \mathrm{~min}$. Then, the backstop was removed, and the densified biomass was extruded out. The force on the shaft, displacement of the shaft, and the strain of the single die wall were recorded. The produced pellets were kept in sealed plastic bags, and the pressure ratio, pellet density, and specific energy consumption were calculated for further analysis.

Table 1. Factor Level Codes

\begin{tabular}{|c|c|c|c|c|c|}
\hline Factors & \multicolumn{4}{|c|}{ Levels } \\
\hline Particle size & \multicolumn{2}{|c|}{ Coarse } & \multicolumn{3}{c|}{ Fine } \\
\hline Compression rate $(\mathrm{m} / \mathrm{s})$ & \multicolumn{2}{|c|}{$3.33 \times 10^{-4}$} & \multicolumn{2}{|c|}{$8.33 \times 10^{-4}$} & \multicolumn{2}{|c|}{$1.33 \times 10^{-3}$} \\
\hline Moisture content (\%) & $5 \pm 1$ & $10 \pm 1$ & $15 \pm 1$ & $20 \pm 1$ & $25 \pm 1$ \\
\hline
\end{tabular}

\section{Pressure Ratio}

The main function of the compression force is to overcome friction and to compress the biomass. The force used to compress biomass is the effective compression force, which equals the force on the backstop. To investigate the relationship between the effective compression force and inner pressure, the effective compression force is converted to effective compression pressure using Eq. 6,

$$
P_{\mathrm{ne}}=\frac{F_{\mathrm{b}}}{\pi R_{\mathrm{i}}^{2}}
$$

where $P_{\text {ne }}$ is the effective compression pressure $(\mathrm{Pa})$ and $F_{\mathrm{b}}$ is the force on backstop $(\mathrm{N})$, 
$R_{\mathrm{i}}$ is the radius of the inner die wall (m).

The pressure ratio was calculated from Eq. 7,

$$
R_{\mathrm{p}}=\frac{P_{\mathrm{i}}}{P_{\mathrm{ne}}}
$$

where $R_{\mathrm{p}}$ is the ratio of inner pressure versus compression pressure.

The maximum pressure was defined as Eq. 8,

$$
M R_{\mathrm{p}}=\operatorname{MAX}\left(R_{\mathrm{p}}\right)
$$

where $M R_{\mathrm{p}}$ is the maximum ratio of inner pressure versus compression pressure.

\section{Pellet Density}

When a pellet is produced, its dimension and weight are tested with a Vernier caliper and an electronic scale, respectively. The pellet density is obtained by Eq. 9 .

$$
\rho=\frac{m}{\pi r_{\mathrm{p}}^{2} l}
$$

where $\rho$ is the pellet density $\left(\mathrm{kg} / \mathrm{m}^{3}\right), m$ is the mass of a pellet $(\mathrm{kg})$, and $r_{\mathrm{p}}$ and $l$ are the radius and length of a pellet $(\mathrm{m})$.

\section{Specific Energy Consumption}

The specific energy consumption is given by Eq. 10,

$$
E_{\mathrm{s}}=\frac{1}{m} \int_{0}^{L} F_{\mathrm{n}} \mathrm{d} x
$$

where $E_{\mathrm{s}}$ is the specific energy consumption $(\mathrm{J} / \mathrm{kg}), m$ is the mass of a pellet $(\mathrm{kg}), L$ is the maximum displacement of the pressing shaft $(\mathrm{m})$, and $F_{\mathrm{n}}$ is the compression force $(\mathrm{N})$.

\section{RESULTS AND DISCUSSION}

\section{Pressures During a Single Trial}

Based on the experimental data and Eq. 5, the change of the compression pressure and inner pressure during every trial was obtained. Results showed that the plots of inner pressure had similar shapes with the compression pressure in previous studies (Holm et al. 2006; Xia et al. 2019). The pressure curve is divided into compression periods and relaxation periods. Both pressures increased linearly in the initial part of the compression period, then increased exponentially in the remainder of the compression period (Holm et al. 2006). It was also observed that curves of the pressure ratio presented similar shapes. Randomly, one group of data was chosen and plotted in Fig. 7 to show how the pressures and pressure ratio changed during a densification process. It was the fine wheat straw that was compressed in this group. The moisture content was $10 \% \pm 1 \%$, and the compression rate was $1.33 \times 10^{-3} \mathrm{~m} / \mathrm{s}$. In the compression period, both the pressures increased. However, the pressure ratio increased first and then decreased. This phenomenon showed that the inner pressure increased faster at the beginning of the compression period, while the effective compressive pressure increased faster in the end. In the relaxation period, both the pressures decreased and the pressure ratio was almost constant. The change rates of the pressures were the same. Therefore, the pressure change during the relaxation period was isotropic. 


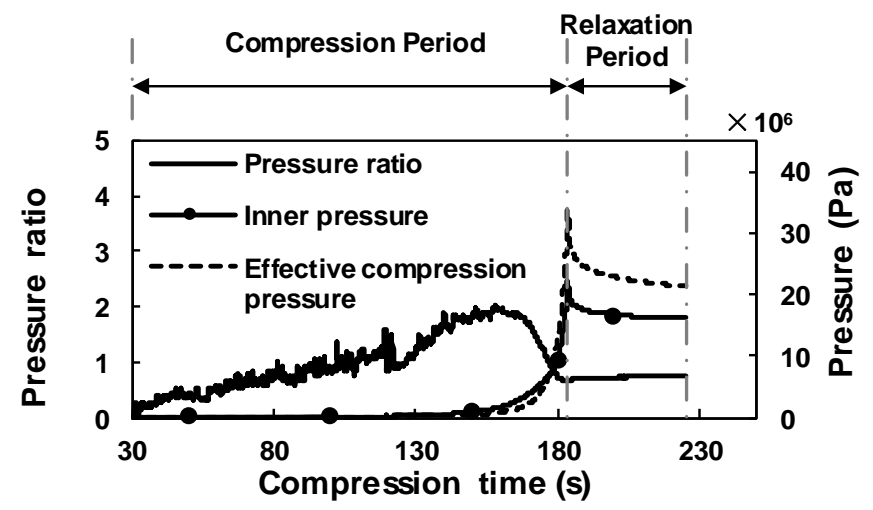

Fig. 7. Typical curves of compression pressure and pressure ratio

To investigate the effects of the three factors on the inner pressure, the pressure ratios during the relaxation period will be discussed in the next three sections. Furthermore, the pellet density and specific energy consumption will also be discussed to make comparisons with the pressure ratio. There were three duplications for each trial, and the average value was the final result. The maximum errors of the compression ratio, pellet density, and specific energy consumption were $2.9 \%, 2.8 \%$, and $4.3 \%$, respectively. Error bars are included in related plots based on these values.

\section{Effects of the Particle Size}

The pressure ratio, pellet density, and specific energy consumption for different sized materials are plotted in Fig. 8. In this test, the compression rate was $3.33 \times 10^{-4} \mathrm{~m} / \mathrm{s}$, and the moisture content was $10 \%$. It was observed for the three materials that the increase of particle size led to an increase in the pressure ratio and specific energy consumption and a decrease in the pellet density. Thus, the coarse materials were more difficult to be densified than the fine (Kirsten et al. 2016).

The main function of the compression force is to densify the biomass materials and overcome the friction force. The force responsible for densifying the biomass is defined as the effective compression force. Because the compression period ended with the same compression pressure in this study, a high-pressure ratio correlated with a high inner pressure, which may lead to a high friction force between the biomass pellets and the inner die wall. Therefore, more energy was needed to overcome the friction force, and the effective compression force decreased. This explains why the increase of particle size led to an increase in the specific energy consumption and a decrease in the pellet density. The effects of particle size on the pellet density and specific energy consumption were in accordance with previous studies (Wang et al. 2018).

As for the three materials, the pressure ratios presented different orders when the particle size was changed. For the fine materials, the value of wheat straw was the largest; while for the coarse materials, the value of wood shavings was the largest. Therefore, despite that the pressure ratios of the three materials increased with the increased particle size, the amounts varied. Similar phenomena were observed for the pellet density and specific energy consumption. The main components in biomass are lignin, cellulose, and hemicellulose. Proportions of these components varied for different materials. So the mechanical parameters and forces between biomass particles were different. Thus, material types had a large effect on the test data. The pelletizing properties for different biomass materials cannot be evaluated based on the pressure ratio only. 


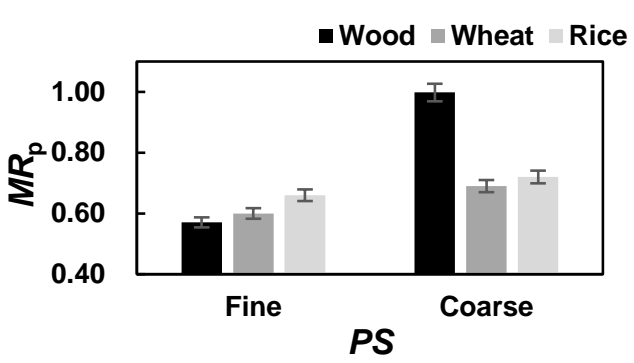

(a)

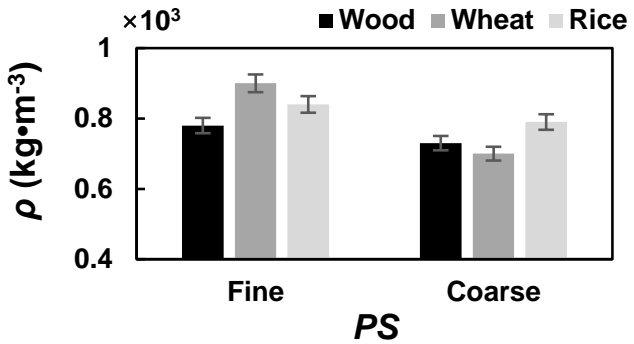

(b)

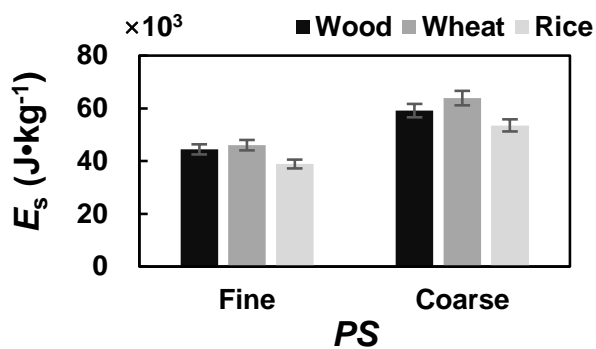

(c)

Fig. 8. Effects of the particle size (PS) on the test data: (a) Effects on the maximum pressure ratio; (b) Effects on the pellet density; (c) Effects on the specific energy consumption

\section{Effects of the Compression Rate}

The effects of the compression rate on the pressure ratio, pellet density, and specific energy consumption are plotted in Fig. 9. In this test, the moisture content was $10 \%$, the particle size of wood shavings was coarse, and the particle size of wheat straw and rice straw was fine. It was observed that the test results decreased with the increase in the compression rate. This phenomenon is different from the effects of the particle size. Therefore, the relationships among the inner pressure, pellet density, and specific energy consumption were different under different technological parameters. Statistical analysis showed that the data could be fitted with linear models, as shown in Table 2. Results showed that the changing rate of the responses was different for the three materials. The maximum pressure ratio and specific energy consumption of the wood shavings, and the pellet density of the rice straw were more sensitive to the change of compression rate.

The pressure ratios of the wheat straw and rice straw were similar in shape (Fig. 9a), but the values for wheat straw were smaller than for rice straw. Furthermore, the wood shavings presented the highest pressure ratio and specific energy consumption, and lowest pellet density (Fig. 9b, c).These phenomena are in accordance with the effects of the particle size. Therefore, the material type had more effect on the pressure ratio compared with the compression rate and particle size. The pelletizing properties of the biomass materials were determined not only by the effective compression force. The effects of the components in different raw materials should also be considered. Different proportions of components could make the mechanical parameters different, such as Young's modulus, Poisson's ratio, damping coefficient, etc. The contact force and friction force between biomass particles could also be different, which will change the solid bridge between biomass particles and the increasing rate of compression force. As a result, energy consumption and pellet density would be affected. For example, the lignin in biomass can act as a natural binder to promote the densification process (Abedi et al. 2018; Nanou et al. 2018). However, some components, such as the waxes on the surface of the wheat straw, may limit the pelletizing properties of the biomass (Stelte et al. 2012). 


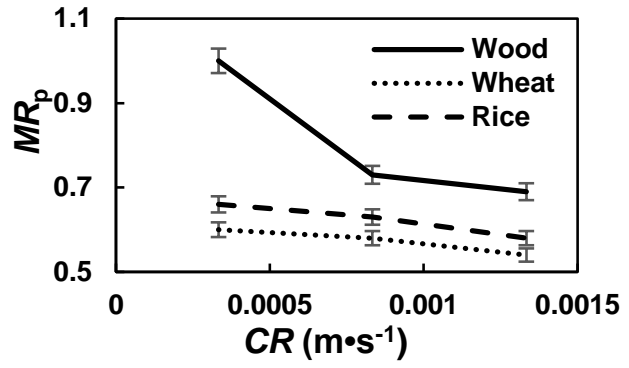

(a)

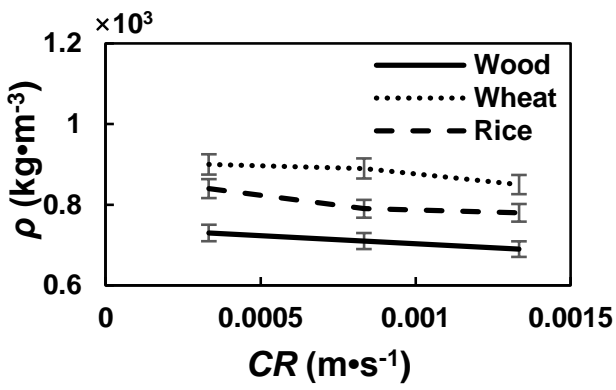

(b)

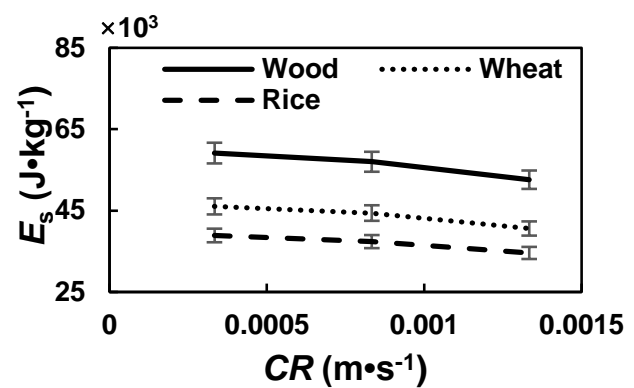

(c)

Fig. 9. Effects of the compression rate $(C R)$ on the test data: (a) Effects on the maximum pressure ratio; (b) Effects on the pellet density; (c) Effects on the specific energy consumption

Table 2. Regression Models for the Effects of Compression Rate

\begin{tabular}{|c|l|c|}
\hline Materials & \multicolumn{1}{|c|}{ Regression model } & $\mathrm{R}^{2}$ \\
\hline \multirow{3}{*}{ Wood Shavings } & $M R_{\mathrm{p}}=-310 C R+1.065$ & 0.8450 \\
\cline { 2 - 3 } & $\rho=(-50 C R+0.922) \times 10^{3}$ & 0.8929 \\
\cline { 2 - 3 } & $E_{\mathrm{s}}=(-6550 C R+61.702) \times 10^{3}$ & 0.9615 \\
\hline \multirow{3}{*}{ Rice Straw } & $M R_{\mathrm{p}}=-80 C R+0.690$ & 0.9796 \\
\cline { 2 - 3 } & $\rho=(-60 C R+0.853) \times 10^{3}$ & 0.8710 \\
\cline { 2 - 3 } & $E_{\mathrm{s}}=(-4300 C R+40.537) \times 10^{3}$ & 0.9713 \\
\hline \multirow{3}{*}{ Wheat straw } & $M R_{\mathrm{p}}=-60 C R+0.623$ & 0.9643 \\
\cline { 2 - 3 } & $\rho=(-40 C R+0.743) \times 10^{3}$ & 1.0000 \\
\cline { 2 - 3 } & $E_{\mathrm{s}}=(-5440 C R+48.213) \times 10^{3}$ & 0.9501 \\
\hline
\end{tabular}

\section{Effects of the Moisture Content}

The effects of the moisture content on the pressure ratio, pellet density, and specific energy consumption are plotted in Fig. 10. The compression rate was $1.33 \times 10^{-3} \mathrm{~m} / \mathrm{s}$, the particle size of wood shavings was coarse, and the particle size of wheat straw and rice straw was fine. Results show that the increase of moisture content led to an increase in the pellet density, but there was a decrease in the specific energy consumption. Statistical analysis showed that the pellet density could be fitted with a linear model, and the specific energy consumption could be fitted with a quadratic model, as shown in Table 3 . The changing rate of pellet density for the wood shavings was the fastest, followed by the rice straw and wheat straw. However, no models were suitable for the maximum pressure ratio. The pressure ratio fluctuated when the moisture content increased. No specific relationship between the pressure ratio and moisture content was observed. 


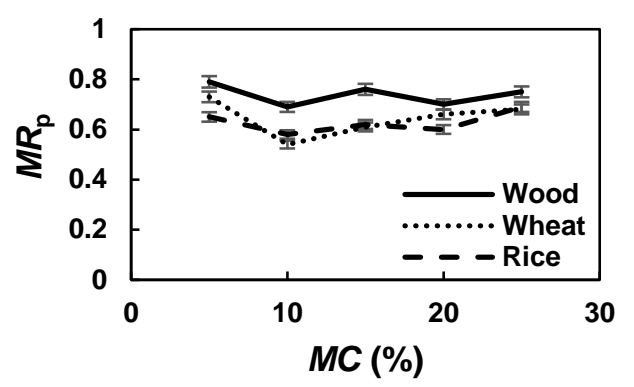

(a)

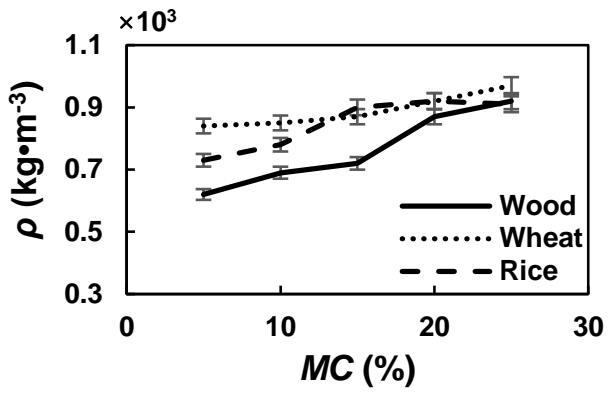

(b)

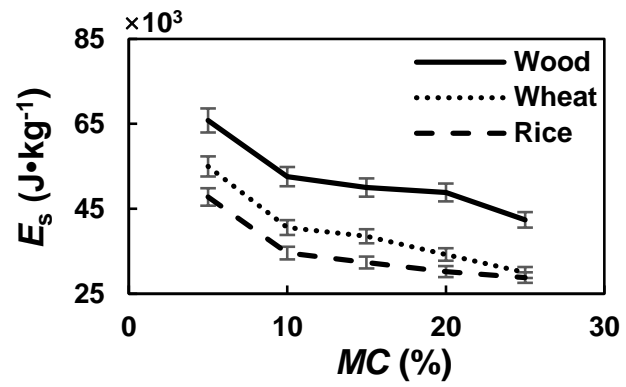

(c)

Fig. 10. Effects of the moisture content $(M C)$ on the test data: (a) Effects on the maximum pressure ratio; (b) Effects on the pellet density; (c) Effects on the specific energy consumption

Table 3. Regression Models for the Effects of Moisture Content

\begin{tabular}{|c|l|c|}
\hline \multirow{2}{*}{ Materials } & \multicolumn{1}{|c|}{ Regression model } & $\mathrm{R}^{2}$ \\
\hline \multirow{2}{*}{ Wood Shavings } & $\rho=15.6 M C+530$ & 0.9548 \\
\cline { 2 - 3 } & $E_{\mathrm{s}}=42.7 M C^{2}-2292 M C+74572$ & 0.9141 \\
\hline \multirow{2}{*}{ Rice Straw } & $\rho=10 M C+698$ & 0.8256 \\
\cline { 2 - 3 } & $E_{\mathrm{s}}=67.7 M C^{2}-2876 M C+59298$ & 0.9463 \\
\hline \multirow{2}{*}{ Wheat straw } & $\rho=6.6 M C+791$ & 0.9229 \\
\cline { 2 - 3 } & $E_{\mathrm{s}}=51.6 M C^{2}-2674 M C+65598$ & 0.9466 \\
\hline
\end{tabular}

The pressure ratios of the wood shavings were larger than that of the wheat straw and rice straw (Fig. 10a). However, the values of the three materials were similar when the moisture content was over 20\%. As shown in Fig. 10(b) and (c), the increase of moisture content led to an increase in the pellet density and a decrease in the specific energy consumption. The densification of wheat straw consumed more energy than rice straw under the same conditions (Fig. 10c). This phenomenon was also observed in the previous two sections. As defined in Eq. 10, specific energy consumption is the total work of compression force. Therefore, a high specific energy consumption means a high average value of the compression force in a whole densification process. In addition, the increasing rate of the compression force for wheat straw is higher than that for rice straw. Thus, the mechanical parameters of wheat straw are different from that of rice straw, as discussed in the previous section.

Moisture is a natural lubricant but not a good binder in the biomass densification process (Zvicevičius et al. 2018). The increasing moisture content can decrease the friction force but increase the liquid bridge force between the biomass particles (Xu et al. 2019). However, because water is incompressible and will be extruded out of the pellets by the 
compression force, the lubrication states and liquid bridge force are unstable in the densification process. Therefore, the distribution of the moisture in the biomass during the densification process is unknown. This may be the reason for the fluctuation of the pressure ratio.

\section{CONCLUSIONS}

In this paper, the change of inner pressure between the materials and die wall was investigated. The relationships between the inner pressure with pellet density and specific energy consumption under different levels of particle size, compression rate, and moisture content were considered. Conclusion were as follows:

1. Like the compression pressure, the inner pressure increased linearly and then exponentially during the compression period. However, compared with the compression pressure, the inner pressure increased faster at the beginning but slower throughout the rest of the compression period. The pressure change during the relaxation period was determined to be isotropic.

2. The increase of the particle size led to an increase in the inner pressure, while the increase of the compression rate led to a decrease in the inner pressure. The inner pressure fluctuated when the moisture content increased.

3. Compared with the particle size and compression rate, the material's type had more effect on the pressure ratio. No monotonic relationship was observed among the pressure ratio, pellet density, and specific energy consumption.

\section{ACKNOWLEDGMENTS}

The authors are grateful for the support of the Natural Science Foundation of Jiangsu Province, Grant No. BK20190473.

\section{REFERENCES CITED}

Abedi, A., Cheng, H., and Dalai, A. K. (2018). "Effects of natural additives on the properties of sawdust fuel pellets," Energ. Fuel 32(2), 1863-1873. DOI: 10.1021/acs.energyfuels.7b03663

Chen, T., Jia H., Zhang, S., Sun, X., Song, Y., and Yuan, H. (2019). “Optimization of cold pressing process parameters of chopped corn straws for fuel," Energies 13(3), Article number 652. DOI: 10.3390/en13030652

Emadi, B., Iroba, K. L., and Tabil, L. G. (2017). "Effect of polymer plastic binder on mechanical, storage and combustion characteristics of torrefied and pelletized herbaceous biomass," Appl. Energ. 198(15), 312-319. DOI: 10.1016/j.apenergy.2016.12.027

Holm, J. K., Henriksen, U. B., Hustad, J. E., and Sorensen, L. H. (2006). "Toward an understanding of controlling parameters in softwood and hardwood pellets production," Energ. Fuel. 20(6), 2686-2694. DOI: 10.1021/ef0503360 
Holm, J. K., Henriksen, U. B., Wand, K., Hustad, J. E., and Posselt, D. (2007). "Experimental verification of novel pellet model using a single pelleter unit," Energ. Fuel 21(4), 2446-2449. DOI: 10.1021/ef0701561

Kirsten, C., Lenz, V., Schröder, H. W., and Repke, J. U. (2016). "Hay pellets-The influence of particle size reduction on their physical-mechanical quality and energy demand during production," Fuel Process. Technol. 148, 163-174. DOI: 10.1016/j.fuproc.2016.02.013

Larsson, S., Lockneus, O., Xiong, S., and Samuelsson, R. (2015). "Cassava stem powder as an additive in biomass fuel pellet production," Energ. Fuel. 29(9), 5902-5908. DOI: 10.1021/acs.energyfuels.5b01418

Nanou, P., Huijgen, W. J. J., Carbo, M. C., and Kiel, J. H. A. (2018). "The role of lignin in the densification of torrefied wood in relation to the final product properties," Biomass Bioenerg. 111, 248-262. DOI: 10.1016/j.biombioe.2017.05.005

Niccolò, P., Patrizia, B., and Eugenio, C. (2018). "Effect of densification conditions on specific energy requirements and physical properties of compacts made from hop cone," Energies 11(9), Article ID 2389. DOI: 10.3390/en11092389

Perry, J., and Aboudi, J. (2003). "Elasto-plastic stresses in thick walled cylinders," J. Press. Vess. - T. ASME 125(3), 248-252. DOI: 10.1115/1.1593078

Puig-Arnavat, M., Ahrenfeldt, J., and Henriksen, U. B. (2017). "Validation of a multiparameter model to investigate torrefied biomass palletization behavior," Energ. Fuel 31(2), 1644-1649. DOI: 10.1021/acs.energyfuels.6b02895

Rudolfsson, M., Borén, E., Pommer, L., Nordin, A., and Lestander, T. A. (2017). "Combined effects of torrefaction and pelletization parameters on the quality of pellets produced from torrefied biomass," Appl. Energ. 191, 414-424. DOI: 10.1016/j.apenergy.2017.01.035

Stelte, W., Clemons, C., Holm, J. K., Ahrenfeldt, J., Henriksen, U. B., and Sanadi, A. R. (2012). "Fuel pellets from wheat straw: The effect of lignin glass transition and surface waxes on pelletizing properties," Bioenerg. Res. 5, 450-458. DOI: $10.1007 / \mathrm{s} 12155-011-9169-8$

Theerarattananoon, K., Xu, F., Wilson, J., Ballard, R., McKinney, L., Staggenborg, S., Vadlani, P., Pei, Z. J., and Wang, D. (2011). "Physical properties of pellets made from Sorghum stalk, corn stover, wheat straw, and big bluestem," Ind. Crop. Prod. 33(2), 325-332. DOI: 10.1016/j.indcrop.2010.11.014

Wang, Y., Wu, K., and Sun, Y. (2017). "Pelletizing properties of wheat straw blending with rice straw," Energ. Fuel. 31(5), 5126-5134. DOI: 10.1021/acs.energyfuels.7b00097

Wang, Y., Wu, K., and Sun, Y. (2018). "Effects of raw material particle size on the briquetting process of rice straw," J. Energy Inst. 91(1), 153-162. DOI:

10.1016/j.joei.2016.09.002

Wang, Y., Sun, Y., and Wu, K. (2019a). "Effects of waste engine oil additive on the pelletizing and pyrolysis properties of wheat straw," BioResources 14(1), 537-553. DOI: 10.15376/biores.14.1.537-553

Wang, Y., Sun, Y., and Wu, K. (2019b). "Methods to determine the interactions between the biomass and the pellet channel during biomass pelletizing process," Waste Biomass Valor. DOI: 10.1007/s12649-019-00755-1

Whittaker, C., and Shield, I. (2017). "Factors affecting wood, energy grass and straw pellet durability - A review," Renew. Sust. Energ. Rev. 71, 1-11. DOI: 10.1016/j.rser.2016.12.119 
Williams, O., Taylor, S., Lester, E., Kingman, S., Giddings, D., and Eastwick, C. (2018). "Applicability of mechanical tests for biomass pellet characterisation for bioenergy applications," Materials 11(8), Article number 1329. DOI: 10.3390/ma11081329

Xia, X., Sun, Y., Wu, K., and Jiang, Q. (2014). "Modeling of a straw ring-die briquetting process," BioResources 9(4), 6316-6328. DOI: 10.15376/biores.9.4.6316-6328

Xia, X., Sun, Y., Wu, K., and Jiang, Q. (2016). "Optimization of a straw ring-die briquetting process combined analytic hierarchy process and grey correlation analysis method," Fuel Process. Technol. 152, 303-309. DOI: 10.1016/j.fuproc.2016.06.018

Xia, X., Zhang, K., Xiao, H., Xiao, S., Song, Z., and Yang, Z. (2019). "Effects of additives and hydrothermal pretreatment on the pelleting process of rice straw: Energy consumption and pellets quality," Ind. Crop. Prod. 133, 178-184. DOI: 10.1016/j.indcrop.2019.03.007

$\mathrm{Xu}, \mathrm{G} ., \mathrm{Li}, \mathrm{M}$., and Lu, P. (2019). "Experimental investigation on flow properties of different biomass and torrefied biomass powders," Biomass Bioenerg. 122, 63-75. DOI: 10.1016/j.biombioe.2019.01.016

Zvicevičius, E., Raila, A., Čiplienè, A., Černiauskienè, Ž., Kadžiulienė, Ž., and Tilvikienè, V. (2018). "Effects of moisture and pressure on densification process of raw material from Artemisia dubia Wall," Renew. Energ. 119, 185-192. DOI: 10.1016/j.renene.2017.12.016

Article submitted: March 4, 2020; Peer review completed: April 18, 2020; Revised version received and accepted: May 7, 2020; Published: May 13, 2020.

DOI: 10.15376/biores. 15.3.4932-4946 